\title{
IMPLEMENTASI SEMANGAT NASIONALISME DALAM PENYELENGGARAAN PENDIDIKAN DAN PEMBUDAYAAN NILAI PANCASILA PADA TINGKAT SEKOLAH DASAR
}

\author{
Mustari $^{1}$, Muhammad akbal ${ }^{2}$, Firman Umar $^{3}$ \\ Fakultas Ilmu Sosial Universitas Negeri Makassar

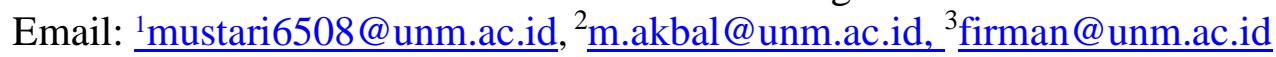

\begin{abstract}
ABSTRAK: Penelitian ini bertujuan (1) untuk mengetahui bentuk program pendidikan dan pembudayaan nilai Pancasila di sekolah dasar. (2) untuk mengetahui bentuk praktik pembelajaran PKn dan bentuk penataan suasana sekolah dalam menanamkan semangat nasionalisme. Jenis penelitian ini adalah penelitian deskriptif, kualitatif dengan fokus pada SDN No. 11 pangkajene Kecamatan Maritengngae Kabupaten Sidrap. Teknik pengumpulan data yang digunakan adalah observasi dan wawancara, dengan teknik analisis datanya adalah analisis deskriptif kualitatif. Hasil penelitian menunjukkan bahwa program pendidikan dan pembudayaan nilai Pancasila dalam, menanakan sikap nasionalisme di SD dilaksanakan dalam dua bentuk yakni praktik pembelajaran PKn dalam kelas dan penataan suasana sekolah. Praktik pembelajaran di dalam kelas dilakukan sejak kegiatan awal pembelajaran sampai pada akhir pembelajaran. Sedangkan bentuk penataan suasana sekolah dilakukan dengan menata sarana dan prasarana yang dapat memotivasi anak dalam menanamkan sikap nasionalisme, seperti menata ruang kelas dengan memasang gambar-gambar pahlawan pada dinding kelas, memasang bendera merah putih didepan kelas. Penataan di luar kelas, seperti menata tempat wudhu, kebersihan kamar kecil mushallah mini, menata kantin jujur, apotik hidup, usaha kesehatan sekolah, pembudayaan salam semut antara siswa dengan guru, siswa dengan siswa.
\end{abstract}

\section{KATA KUNCI: Nasionalisme, Pembudayaan Nilai-nilai Pancasila}

ABSTRACT: This study aims (1) to find out the form of education programs and the cultivation of Pancasila values in elementary schools. (2) to know the form of PKn learning practice and the form of school atmosphere arrangement in instilling the spirit of nationalism. This type of research is descriptive, qualitative research with a focus on SDN No. 11 pangkajene Maritengngae Subdistrict Sidrap. Data collection techniques used are observations and interviews, with the data analysis technique is qualitative descriptive analysis. The results showed that the education program and the cultivation of Pancasila values in, supporting nationalism attitudes in elementary schools are implemented in two forms, namely the practice of learning PKn in the classroom and structuring the school atmosphere. The practice of learning in the classroom is carried out from the beginning of the learning activity until the end of the learning. While the form of school atmosphere arrangement is done by arranging facilities and infrastructure that can motivate children in instilling nationalism, such as arranging the classroom by putting pictures of heroes on the walls of the classroom, putting red and white flags in front of the class. Ppenataan outside the classroom, such as arranging ablution place, cleanliness of the restroom mushallah mini, arranging honest canteen, live pharmacies, school health efforts, cultivation of ant greetings between students and teachers, students with students.

KEYWORDS: Nationalism, Culture of Pancasila Values 


\section{PENDAHULUAN}

Dalam Pancasila terkandung berbagai nilai, gagasan dasar dan tatanan yang baik dan telah disepakati bersama sebagai pedoman dalam kehidupan bermasyarakat, berbangsa dan bernegara. Nilai-nilai Pancasila tersebut harus dipahami, dihayati dan diamalkan dalam kehidupan sehari-hari. Upaya pemahaman, penghayatan dan pengamalan Pancasila di sekolah dilakukan dengan menyelenggarakan kegiatan pendidikan dan pembelajaran secara umum dengan berbagai kegiatan mata pelajaran, dan secara khusus melalui mata pelajaran Pendidikan Kewarganegaraan (PKn).

Fungsi dan tujuan pendidikan sebagaimana tersebut dalam UndangUndang Nomor 20 tahun 2003 tentang Sistem Pendidikan Nasional. yaitu mengembangkan kemampuan dan membentuk watak serta peradaban bangsa yang bermartabat dalam rangka mencerdaskan kehidupan bangsa. Sedangkan tujuan pendidikan adalah untuk mengembangkan potensi peserta didik agar menjadi manusia yang berimat dan bertaqwa kepada Tuhan Yang Maha Esa, berakhlak mulia, sehat, berilmu, cakap, kreatif, mandiri dan menjadi warga negara yang demokratis dan bertanggung jawab. akan tetapi dalam kenyataannya menunjukkan bahwa pelaksanaan pembelajaran di sekolah belum memenuhi harapan sesuai dengan fungsi dan tujuan pendidikan tersebut.

Banyak kejadian yang ada dalam kehidupan bermasyarakat, berbangsa dan dan bernegara yang patut menjadi perhatian serius sebagai bahan perenungan dalam memperbaiki pelaksanaan kegiatan pendidikan dan pembelajaran di sekolah selama ini terutama dalam upaya membudayakan nilai-nilai Pancasila.

Dalam lingkungan sekolah, sering kita dapati kejadian perkelahian antar siswa baik secara perorangan maupun secara massal yang terjadi hanya karena masalah sepele. Melakukan perusakan terhadap sarana dan prasarana sekolah ketika tidak naik kelas. tidak menjadi pimpinan pada suatu perkumpulan di sekolah atau juga kalah dalam pertandingan/ perlombaan, baik antara kelas maupun antar sekolah. Perilaku membolos, tidak masuk sekolah hanya karena ingin pergi ke tempat hiburan, merupakan pemandangan yang sering terjadi di lingkungan beberapa sekolah bahkan sampai pada perilaku yang membahayakan, seperti mengkonsumsi obat-obatan terlarang.

Di luar sekolah, di masyarakat kita temukan banyak kejadian pemilihan kepala daerah berubah menjadi kerusuhan, pembakaran kantor, rumah warga, mobil karena calon yang diusung tidak terpilih. Kita jumpai pula kejadian perkelahian warga antur kampung karena adanya kesaIahpahaman tentang permasalahan sepele, perbedaan keyakinan, perbedaan suku, dan . perbedaan pandangan.

Mencermati situasi dan kondisi yang ada di lingkungan masyarakat dan lingkungan sekolah, hal itu menunjukkan masih rendahnya semangat nasionalisme sebagai bangsa Indonesia yang berideologikan Pancasila. Maka patutlah kita menata dan dan merevitalisasi model pendidikan dan pembudayaan nilai -nilai Pancasila yang selama ini berjalan, dari pembelajaran yang bersifat indoktrinal menuju ke arah pembudayaan yang lebih demokratis dan lebih berorientasi pada pengalaman dalam kehidupan sehari-hari melalui perubahan visi, misi dan strategi pedagogis yang sesuai untuk pendidikan dan dan pemberdayaan nilai-nilai Pancasila.

Oleh karena iitu Program Pembudayaan Nilai-Nilai Pancasila melalui pembelajaran Pendidikan 
Kewarganegaraan Sekolah Dasar pada sejumlah daerah rintiasan di tanah air, dalam hal ini termasuk propinsi Sulawesi Selatan. Salah satu kabupaten yang diangkat untuk melihat program tersebut, adalah Kabupaten Sidrap dengan fokus pada satu sekolah dasar.

\section{PENGERTIAN UMUM NASIONALISME}

Dalam Ensiklopedia Ilmu-ilmu sosial (2000: 694). Nasionalisme adalah keyakinan bahwa setiap bangsa mempunyai hak dan kewajiban untuk membentuk dirinya sebagai negara. Selanjutnya dalam Azyumardi Azra (2003; 24) menjelaskan bahwa konsep paham ideologi kebangsaan yang biasa disebut dengan dengan nasionalisme, kemudian lahir konsep-konsep turunannya seperti bangsa (nation), negara (state) dan gabungan keduanya menjadi konsep negara -bangsa (nation state). Sebagai komponen-komponen yang membentuk identitas nasional atau kebangsaan . Mengacu pada awal tumbuhnya nasinalisme secara umum , maka nasionalisme dapat dikatakan sebagai sebuah situasi kejiwaan dimana kesetiaan seseorang secara total diabdikan langsung kepada negara bangsa atas nama sebuah bangsa. Dalam perkembangan selanjutnya, para pengikut nasionalisme ini berkeyakinan bahwa persamaan cita-cita yang mereka miliki dapat diwujudkan dalam sebuah identitas politik atau kepentingan bersama dalam bentuk sebuah wadah yang disebut bangsa (nation) dengan demikian bangsa atau nation merupakan suatu badan atau wadah yang didalamnya terhimpun orang-orang yang memiliki persamaan keyakinan dan persamaan lain yang mereka miliki seperti ras, etnis, agama, bahasa dan budaya.

\section{NASIONALISME INDONESIA}

Tumbuhnya paham nasionalisme atau paham kebangsaan Indonesia tidak bisa dilepaskan dari situasi politik dekade abad ke- 20. Pada waktu itu semangat menentang koionialisme belanda mulai bermunculan di kalangan pribumi. Citacita bersama untuk merebut kemerdekaan menjadi sangat umum dikalangan tokohtokoh perguruan nasional untuk memformulasikan bentuk nasionalisme yang sesuai dengan kondisi masyarakat Indonesia. Mereka sepakat tentang perlunya suatu konsep nasionalisme Indonesia merdeka. tapi mereka berbeda dalam persoalan nilai atau watak nasionalisme Indonesia. Secara garis besar terdapat tiga pemikiran besar tentang watak nasionalisme Indonesia yang terjadi pada zaman kemerdekaan yakni paham keislaman, marxisme, dan nasionalisme Indonesia.

Nasionalisme Indonesia dan konsep-konsep turunannya yang dirumuskan oleh para founding father berkelindang dengan konsep-konsep lanjutan lainnya, seperti konsep negara yang lebih di konkritkan menjadi bentuk dan struktur negara Indonesia yang berbentuk Republik. Konsep-konsep tersebut dirumuskan dalam ketetapan Undang-Undang Dasar 1945.

Nasionalisme Indonesia pada dasarnya berwatak inklusif dan berwawasan kemanusiaan. Pada perkembangan selanjutnya, watak nasionalisme Indonesia yang dirmuskan oleh tokoh-tokoh nasionalis mempengaruhi konsep pokok selanjutnya tentang negara bangsa, warga negara dan dasar negara Indonesia atau yang kemudian disebut dengan ideologi Pancasila. 
NASIONALISME SEBAGAI

KONSEP KEBANGSAAN BERUPA CINTA BANGSA DAN CINTA

TANAH AIR

Nasionalisme sebagai konsep kebangsaan berupa cinta bangsa dan cinta air, telah dikenal bangsa Indonesia Sejak lama, tetapi tentu saja masih dalam bentuk yang sederhana, samar-samar dan meliputi lingkup yang sempit (kedaerahan -tradisional) sebagai anthitesis terhadap kolonialisme misalnya telah melahirkan perlawanan di daerah-daerah serta bentu-bentuk penolakan lainnya, yang intinya menolak sistern kolonial (kolonialisme), konsep cinta bangsa dan tanah air ini baru kemudian pada awal ke 20 dikembangkan oleh kaum terpelajar Indonesia hasil pendidikan, menjadi konsep lingkup yang lebih luas, meliputi seluruh tanah air dan penduduk yang mendiaminya.

Nasionalisme adalah sebuah paham, sehingga membawa konsekuensi agar dapat memberikan manfaat dan hasil yang konkrit perlu adanya seperangkat alat bantu yang dapat mendukung dan memperjuangkan apa yang menjadi ideide dari paham tersebut. Dalam hal ini para pelajar Indonesia sebagai kelompok cendekiawan (kelompok elite modern) menyadari sepenuhnya bahwa seperangkat alat yang dibutuhkan itu tidak lain adalah sebuah organisasi. Organisasi yang teratur dan modern diperlukan guna mewujudkan semangat nasionalisme itu. Kesadaran semacam ini pulalah yang kemudian telah memberikan motivasi pada sekelompok pemuda pelajar di stovia yang dipimpin oleh pemuda Sutomo untuk mendirikan perkumpulan Budi utomo, sebagai organisasi pertama yang menjadi perintis atau pelopor bagi lahirnya organisasiorganisasi lain baik di dalam negeri maupun luar negeri yang merupakan pergerakan Nasional Indonesia.
Nasionalisme sebagai manifestasi kesadaran bernegara tumbuh di negara merdeka. Sesungguhnya justru di negara yang merdeka nasionalisme dapat berkembang secara leluasa menurut kemampuan dan kemauan para warga negara sendiri tanpa mengalami tekanan dari pihak lain. Sampai seberapa jauh nasionalisme itu bebas dan berkembang, bergantung kepada bagaimana penerapan cara berfikir nasional para warga negaranya. Yang dimaksud cara berfikir nasional adalah sikap seseorang terhadap kesadaran bernegara cara berfikir nasional mempunyai ciri khusus, berupa norma obyektif mengutamakan kepentingan kehidupan nasional. Segala perbuatan baik bersifat keluar maupun kedalam diukur dengan norma tersebut. Apakah suatu tindakan itu menguntungkan kehidupan nasional apakah justru merugikan, yang merugikan perlu dan wajib ditinggalkan, jika kesadaran bernegara memang terdapat dalam hati warga negara yang bersangkutan . Dengan dalih apapun perbuatan yang merugikan kehidupan nasional wajib ditinggalkan.

\section{PEMBUDAYAAN NILAI-NILAI PANCASILA MELALUI PRAKTIK BELAJAR KEWARGANEGARAAN DI SEKOLAH DASAR}

Secara historis konstitusional Pembudayaan Nilai-nilai Pancasila melalui institusi pendidikan nasional sesungguhnya sudah ada sejak tahun 1945 yang ditujukan untuk mencerdaskan kehidupan bangsa, sebagaimana tersurat dalam pembukaan UUD 1945 alinea ke 4 yaitu seluruh tumpah darah Indonesia dan untuk memajukan kesejahteraan umum, mencerdaskan kehidupan bangsa ... ". Namun dalam perjalanan instrumentasi dan praksisnya sangat fluktuatif, sesuai dengan irama dan iklim sosial politik terkait dengan kebijakan politik 
kenegaraan pada setiap kurun waktu kepemimpinan nasional .

Bila dicermati dalam perkembangannya, secara implisit nilai nilai Pancasila telah ada dalam berbagai peraturan perundang-undangan. Misalnya, dalam usulan BP KNIP tanggal 29 Desember 1945 dikemukakan bahwa " Pendidikan dan pengajaran harus membimbing murid-murid menjadi warga negara yang sejati, bersedia menyumbangkan tenaga dan pikiran untuk negara dan masyarakat " dengan ciri-ciri sebagai berikut :

"Perasaan bakti kepada Tuhan Yang Maha Esa; perasaan cinta kepada negara; perasaan einta kepada bangsa dan kebudayaan; perasaan berhak dan wajib ikut memajukan negaranya menurllt pembawaan dan kekuatannya; keyakinan bahwa orang menjadi bagian tak terpisahkan dari keluarga dan masyarakat ; keyakinan bahwa orang hidup bermasyarakat harus tunduk pada tata tertib; keyakinan bahwa pada dasarnya manusia itu sama derajatnya sehingga sesama anggota masyarakat harus saling menghormati, berdasarkan rasa keadilan dengan berpegang teguh pada harga diri; dan keyakinan bahwa negara memerlukan warga negara yang rajin bekerja, mengetahui kewajiban, dan jujur dalam pikiran dan tindakan" (Djojonegoro, 1996).

Selanjutnya dlam UU No. 4 tahun 1950 dalam Bab II Pasal 3 (Djojonegoro, 1996) dirumuskan secara eksplisit menjadi "...membentuk manusia susila yang cakap dan warga negara yang demokratis, serta bertanggung jawab tentang kesejahteraan masyrakat dan tanah air" dan dalam UU No 12 Tatum 1954 yang dilengkapi denga keputusan Presiden Rl No.145 Tahun 1965 rumusannya di ubah menjadi " melahirkan warga negara yang sosialis, yang bertanggung jawab atas terselenggaranya masyarakat sosialis
Indonesia, adil dan makmur baik spiritual maupun materil dan yang berjiwa Pancasila ."

Selain itu, di dalam pasal 4 UU nomor 20 tahun 2003 tentang sistem pendidikan nasional dinyatakan bahwa "Pendidikan diselenggarakan secara demokratis dan berkeadilan serta tidak diskriminatif dengan menjujung tinggi hak asasi manusia, nilai keagamaan, nilai kultural, dan kemajemukan bangsa" Walaupun dalam rumusan tujuan itu tidak terdapat kata nilai-nilai Pancasila, tapi makna yang terkandung dalam rumusan tersebut sesungguhnya merupakan esensi dari pendidikan nilai-nilai Pancasila. Dengan kata lain sejak tahun 1945 sampai sekarang instrumen perundangan sudah menempatkan pendidikan nilai Pancasila sebagai bagian integral dari pendidikan nasional.

Dalam tatanan instrumentasi kurikuler yaitu kurikulum di sekolah terdapat mata pelajaran yang secara khusus mengemban misi pendidikan nilai-nilai Pancasila, yakni mata pelajaran civics (kurikulum 1957/1962); pendidikan kemasyarakatan yang merupakan integrasi sejarah; ilmu Bumi dan Kewarganegaraan (Kurikulum 1964). Pendidikan Kewargaan negara, yang merupakan perpaduan ilmu Bumi, sejarah Indonesia dan Civics (Kurikulum 1968/1969); Pendidikan kewargaan negara dan civics dan Hukum (1973); Pendidikan Moral Pancasila atau PMP (Kurikulum 1975 dan 1984); dan pendidikan Pancasila dan kewarganegaraan atau PPKn (kurikulum 1994). Kemudian pendidikan kewarganegaraan dan pengetahuan sosial (PKPS) dalam kurikulum berbasis Kompetensi (KBK) 2004 Selanjutnya Pendidikan Kewarganegaraan (Standar isi 2006) Sementara itu dalam kehidupan masyarakat terdapat berbagagi paket pentaran P4 (sejak 1970-an) yang juga 
mengandung tujuan dan materi pendidikan nilai-nilai Pancasila.

Ternyata dirasakan bahwa pendidikan nilai-nilai Pancasila ini belum memberikan hasil yang menggembirakan, Indikator yang kasat mata dapat kita amati dan rasakan bahwa sampai hari ini antara lain: kebebasan mengeluarkan pendapat yang cenderung anarkis, pelanggaran HAM di manamana, komunikasi sosial politik yang cenderung asal menang sendiri, hukum yang terkalahkan, dan kontrol sosial yang sering lepas tata krama, serta terdegradasinya kewibawaan para pejabat negara.

Persoalannya adalah, mengapa dampak instruksional dan dampak pengiring nilai-nilai Pancasila tersebut dalam kenyataan fenomena sosial kultural dan sosial politik, terkesan tidak menggembirakan? Mungkin juga ada benarnya yang disimpulkan oleh Gandal dan Finn (1992) walaupun bukan dianggap taken for granted or ignored, tapi kasus di Indonesia besar kemungkinan karena tidak intensifnya penanganan pendidikan Pancasila pada tataran praksis. Berbagai penelitian seperti dihimpun oleh Djahiri, dkk (1998) menunjukkan bahwa praksis pendidikan Pancasila, dalam hal ini melalui PMP/PPKn/ Penataran P-4 cenderung menitikberatkan pada penguasaan aspek pengetahuan dan mengabaikan pengembangan sikap dan keterampilan kewarganegaraan, dengan menggunakan pendekatan ekspositori yang cenderung indokrinatif.

Secara tradisional, khususnya di Indonesia, baik dalam rangka mata pelajaran Pendidikan Pancasila dan Kewarganegaraan (PPKn) atau sebelumnya Pendidikan Moral Pancasila (PMP) maupun dalam rangka penataran P4 , pembudayaan nilai-nilai Pancasila terkesan lebih banyak diajarkan atau tought dan bukan dipelajari atau learned dengan peran guru /dosen/ penatar/manggala yang lebih dominan. Karena itu situasinya kelasnya pun, dengan meminjam istilah Flanders (1972) lebih bersifat dominatif dan bukan integratif. Dampak lnstruksional dan pengiringnya pun tentu tak bisa dielakkan lagi lebih bersifat pengetahuan atau knowledge oriented. Oleh karena itu dapat dipahami mengapa bangsa Indonesia dalam berbagai lapisan sosial terkesan belum mengamalkan nilai-nilai Pancasila .

Selain itu, lingkungan sosial kultural dan sosial politik yang tidak kondusif krena semenjak tahun ] 945 sampai 8aat ini masih menunjukkan ciri undemocratic democracy (Sumantri: 1998) , yakni suatu keadaan dimana perangkat demokrasir.ya sudah ada, tetapi semangat dan perwujudannya masih jauh dari cita-cita demokrasi, yang memang dirasakan selalu menimbulkan kontroversi atau paradoksal antara realita dengan norma, antara yang dilihat, di dengar dan dialami dengan yang diajarkan, diceramahkan dn dipidatokan. Secara psikologis dan sosial keadaan seperti itu tidak menguntungkan bagi proses pendidikan karena keadaan lingkungan sekitar hanya memberi negative reinforcment atau penguatan negatif terhadap tumbuhnya sikap dan perilaku yang positif.

Tantangan konseptual tersebut mengimpiikasi peril! dibangunnya paradigma pendidikan (pembudayaan) nilai-nilai Pancasila yang merupakan bagian integral dari proses pendidikan secara keseluruhan dan proses kehidupan bermasyarakat, berbangsa dan bemegara sebagai suatu keutuhan. Oleh karena itu pada tataran instrumental makro school based values education dan society-based values education seyogyanya dirancang secara sistemik denganm sistem pendidikan nasional secara keseluruhan, dan secara praksis seyogyanya diciptakan 
jaringan dan iklim sosial kultural yang memungkinkan terjadinya interaksi fungsional pedagogis kegiatan-kegiatan di sekolah dan di luar sekolah.

Menurut Winaputra (2003) "Salah satu unsur budaya kewarganegaraan adalah civic virtue atau kebajikan atau akhlak kewarganegaraan yang mencakup keterlibata aktif warga negara, hubungan kesejajaran/egaliter, saling percaya dan toleran, kehidupan yang kooperatif, solidaritas dan semangat kemasyarakatan. Semua unsur akhlak kewarganegaraan itu diyakini akan saling memupuk dengan kehidupan civic community atau civic society atau masyarakat madani unbtuk Indonesia. Dengan kata lain tumbuh dan berkembangnya masyarakat madani bersifat interaktif dengan tumbuh dan berkembangnya akhlak kewarganegaraan (civic virtue) yang merupakn unsur utama dari budaya kewarganegaraan. (civic kulture)". Gleh karena itu diperlukan adanya dan berperannya pendidikan nilainilai Pancasila yang mampu mengembangkan akhlak kewarganegaraan, yang dalam waktu bersamaan mampu memberi kontribusi terhadap berkembangnya budaya kewarganegaraan yang menjadi inti dari masyarakat madani.

Untuk menjwab pertanyaan "model pembelajaran seperti apa yang dapat brmakna bagi proses pembudayaan"? Sebaiknya digunakan proses pembelajaran yang merangsang, menantang dan menyenangkan seperti yang dikemukakan oleh Whitehead sampai pada tingkat "joy of discovery" yaitu melibatkan proses pembudayaan dan proses penguasaan seni menggunakan ilmu pengetahuan. Dalam kaitan ini, UNESCO melalui International Commision on Education for the Twenty First Century (1996) mengusulkan empat pilar belajar yaitu" learning to know, learning to do, learning to be, and learning to live together"

Menerapkan empat pilar tersebut berarti bahwa proses pembelajaran memugkinkan peserta didik berkesempatan menguasai cara memperoleh pengetahuan, berkesempatan menerapkan pengetahuan yang dipelajarinya, berkempatan untuk menemukan jati dirinya dan berkesempatan untuk berinteraksi secara aktif dengan sesama peserta didik. Model pemhelajaran seperti ini hanya dapat berlangsung dengan tenaga guru yang profesional, peralatan yang memadai sesuai dengan materi yang terpilih dan waktu yang cukup tanpa hams mengejar target kurikulum.

Disamping itu, guru harus mampu mengintegrasikan setiap potensi yang dimiliki peserta didik, lingkungan kelas dan sekolah, serta berbagai unsur yang terlibat dalam pendidikan, mulai dari orang tua peserta didik, tokoh masyarakat, komite sekolah, dan institusi yang terlibat aktif dalam pendidikan.

Hasil dalam Penelitian ini menunjukkkan bahwa bentuk penyelenggaraan program pendidikan dan pembudayaan nilai Pancasila di Sekolah Dasar Negeri No 11 pangkajene Sidrap sudah dilaksanakan melalui dua bentuk kegiatan yakni:

Praktik Belajar Kewarganegaraan (PBK) merupakan pendekatan yang dilaksanakan pada mata pelajaran Pendidikan Kewarganegaraan, dan Kegiatan dalam bentuk Penataan Suasana Sekolah Untuk menciptakan suasana sekolah yang mampu mendukung pembiasaan dan pembudayaan nilai-nilai Pancasila, dilakukan dengan penataan sarana dan prasarana pendukung sehingga aktivitas pembiasaan dan pembudayaan nilai-nilai Pancasila tersebut dapat berjalan sesuai dengan harapan. 
$\begin{array}{rr}\text { Berikut ini adalah bentuk } \\ \text { program-program yang } & \text { sudah }\end{array}$ dilaksanakan di SDN No. 1 Pangkajene, yang terkait dengan pendidikan dan pembudayaan nilai Pancasila adalah sebagai berikut:

1. Peningkatan mutu proses pembelajaran untuk guru

2. Kegiatan Kepramukaan

3. Kegiatan Usaha Kesehatan Sekolah (UKS)

4. Pengadaan Kantin jujur

5. Kegiatan keagamaan dan penataan Ruang Shalat (Mushallah mini)

6. Penataan ruang perpustakaan

7. Penataan apotik hidup

8. Penataan ruang ICT

9. Penataan-penataan lain khususnya dalam menciptakan suasana sekolah yang bernuansa memotivasi siswa dalam menanamkan semangat nasionalisme.

Peningkatan mutu proses pembelajaran terus menerus diupayakan dengan meningkatkan mutu guru, baik dari segi peningkatan pendidikan formalnya maupun peningkatan melalui pendidikan dan pelatihan-pelatihan menurut Kepala Sekolah bahwa SDN No. 11 Pangkajene, memiliki guru sebanyak 95\% berstatus sarjana (S-1) dan 4 (empat) orang guru yang sudah mengikuti sertifikasi guru, dan bagi guruguru yang belum bersertifikasi terusmenerus diberikan kesempatan untuk mengikuti pelatihan-pelatihan.Terkait dengan program pendidikan dan pembudayaan nilai Pancasila, kegiatan yang sering diikuti oleh guru adalah pelatihan/penataran Imtak.

\section{PENUTUP}

Pelasanaan

program

penyelenggaraan pendidikan dan pembudayaan nilai Pancasila di SDN No. 11 Pangkajene Kecamatan Maritengngae Kabupaten Sidrap sudah terlaksana dengan baik, hal tersebut tampak dalam kegiatan proses praktik pembelajaran yang dilaksanakan di Kelas IV, Kelas V dan Kelas VI dengan materi pelajaran IPA, IPS dan PKn, yang pada hakikatnya mengintegrasikan nilai-nilai pembudayaan Pancasila diselah-selah proses pembelajaran berlangsung dengan berbagai model pembelajaran. Bentuk praktik pembelajaran $\mathrm{PKn}$ dalam penanaman sikap nasionalisme di SDN No. 11 Pangkajene, dilakukan dengan menerapkan/menyesuaikan model pembelajaran dengan materi yang disajikan dan penanaman sikap nasionalisme dilakukan sejak kegiatan awal sampai kegiatan akhir pelajaran.Sedangkan penanaman sikap nasionalisme melalui; penataan suasana sekolah juga sudah dilakukan dengan menata pekarangan sekolah dengan berbagai bentuk variasi yang memberi motivasi siswa, penataan berbagai sarana/ruang yang mencerminkan penanaman nilai Pancasila.

\section{DAFTAR PUSTAKA}

Anonim, 2007. Pembudayaan Nilai-Nilai Pancasila melalui Praktik Belajar Kewarganegaraan di Sekolah Dasar. Depdiknas Jakarta.

Anonim, 2002. Kapita Selekta Pendidikan Pancasila, bagian Proyek Peningkatan Tenaga Akademik Direktorat Jenderal Pendidikan Tinggi. Depdiknas. Jakarta

Azyumardi Azra. 2003. Pendidikan Kewargaan. Prenada Media, Jakarta

A. Ubaedillah. 2016. Pendidikan Kewarganegaraan (Civic Education) Pancasila, Demokrasi dan Pencegahan Korupsi. Jakarta: Prenadamedia Group. 
Achmad Kosasih Djahiri. 1985. Strategi Pengajaran Afektif-Nilai-Moral VCT dan Games dalam VCT. Bandung: FPIPS IKIP Bandung. Ahmad Jamalong, dkk. 2019. Pendidikan Pancasila dan Kewarganegaraan di Perguruan Tinggi. Depok: PT RajaGrafindo Persada.

Aim Abdul Karim, dkk. 2001. Civicus; Jurnal Ilmu Politik, Hukum, $P K n$. Bandung: FPIPS Universitas Pendidikan Indonesia.

Bambang Daroeso. 1986. Dasar dan Konsep Pendidikan Moral Pancasila. Semarang: Aneka Ilmu.

Budi Juliardi. 2016. Pendidikan Kewarganegaraan Untuk Perguruan Tinggi. Depok: Rajawali Pers.

C.S.T. Kansil. 1984. Pengantar Ilmu Hukum dan Tata Hukum Indonesia. Jakarta: PN Balai Pustaka

I Wayan Koyan. 2000. Pendidikan Moral - Pendekatan Lintas Budaya. Jakarta: Dirjen Dikti Depdknas.

Kaelan. 2016. Pendidikan Kewarganegaraan untuk Perguruan Tinggi. Yogyakarta: Paradigma.

Kt. Diara Astawa.2006. Aku warga Negara Indonesia. Pendidikan
Kewarganegaraan Untuk SD dan MI. PT. Musi Perkasa Utama. Jakarta

Mardenis. 2019. Pendidikan Kewarganegaraan dalam Rangka Pengembangan Kepribadian Bangsa. Depok: PT RajaGrafindo Persada.

Raka Joni, 1981. Wawasan Kependidikan. P3G Departemen Pendidikan dan Kebudayaan. Jakarta

Ratna Megawangi. 2005. Membangun SDM Indonesia Melalui Holistic Berbasis Karakter. Jakarta

Winaputra, US. 1996. Perkembangan Pendidikan Kewarganegaraan di Indonesia. Bandung CICED Jakarta.

Soenarjati M \& Cholisin. 1989. Konsep Dasar Pendidikan Moral Pancasila. Yogyakarta: FPIPS IKIP Yogyakarta.

Suparlan Al Hakim, dkk. 2016. Pendidikan Kewarganegaraan dalam Konteks Indonesia. Malang: Madani.

Ujang Charda S. 2019. Pendidikan Kewarganegaraan di Perguruan Tinggi. Depok: PT RajaGrafindo Persada.

Winarno. 2018. Paradigma Baru Pendidikan Kewarganegaraan. Jakarta: Bumi Aksara. 